\title{
RE-SIGNIFY THE DOMESTIC SPACE IN TIMES OF CONFINEMENT FROM THE APPLICATION OF ETHNOGRAPHIC TOOLS AND PERSONAL CENTERED DESIGN
}

\author{
Carlos COBREROS ${ }^{1}$, Mariana MAYA ${ }^{1}$, Stefania BIONDI ${ }^{1}$, X. SÁNCHEZ ${ }^{1}$ and E. \\ ONTIVEROS-ORTIZ ${ }^{2}$ \\ ${ }^{1}$ Tecnologico de Monterrey, Escuela de Arquitectura, Arte y Diseño \\ ${ }^{2}$ Tecnologico de Monterrey, Escuela de Ciencias Sociales y Gobierno
}

\begin{abstract}
The Covid-19 crisis has been described as the "greatest challenge that humankind has faced since the $2^{\text {nd }}$ World War," having an impact on health, society, and the global economy. Houses and domestic spaces are key sites through which COVID-19 is experienced, thus, an interdisciplinary approach is needed. The goal of this research project is to forge an analytical approach while experimenting with micro-ethnography and auto-ethnography tools to analyse how we inhabit the domestic spaces in complex situations of confinement imposition in order to arrive at an outward reflection from within. The project reflects on an innovative social experiment that opens up new paths of design provoking to help us rethink the domestic space. This paper has the objective to compile, compare and explain the processes and results around the characterization of the domestic space, centring on the person in times of confinement through an ethnographic approach.
\end{abstract}

Keywords: Domestic space, confinement, COVID-19, ethnography

\section{INTRODUCTION}

The Covid-19 is impacting not only our health but society and economy globally [1]. In this context, protocols have been proposed such as self-isolation, social distancing, complete lockdown [2], border closures, travel restrictions, school and business closures, and quarantine [3] amongst others.

Social isolation has posed a serious threat to people's physical and mental health [4], causing a decrease in the general well-being [5], experienced by a large part of the population [6]. Emotional fluctuations and psychological discomfort are detected as quarantine duration elongates [7], reducing social connection [4]. Confinement endangers domestic coexistence [8]. Younger adults and women report higher distress during the COVID-19 [4]. For children, isolation entails a substantial risk [9] with direct consequences regarding health, safety, and well-being [10].

\subsection{Domestic space and housing}

The subsequent measures have had implications on how we occupy our habitat and how we relate to the open environment and nature, observing the effects on our physical, mental, and emotional well-being [11]. This global crisis is an opportunity to question the role of designers as to rethink possible alternatives [12].

Houses are key sites through which COVID-19 is experienced [13]. In confinement, houses became the only place we slept, ate, worked, practiced sports, and socialized [14]. The characteristics of the built environment within houses are directly associated with health [15], and well-being [16]. Domestic space designs play a fundamental role in this health crisis [17].

As aforementioned, an interdisciplinary approach is needed [18], and in the school of Architecture, Art and Design of Tec de Monterrey in Mexico the idea of analysing our domestic spaces during confinement seemed a way to look at and re-signify our habitat while in confinement, but also to rethink for the new normal.

The research project "Re-signify the Domestic Space in Times of Confinement," hopes to be a guide for professionals in Design, from an analytical approach, while experimenting with micro-ethnography as 
well as auto-ethnography to analyse how to inhabit domestic spaces inf confinement to arrive at a global reflection. The project reflects on a social innovation experiment that opens new paths to design, provoking the rethinking of the domestic space.

This paper has the objective to compile, compare and explain the processes and results around the characterization of the domestic space, centring on the person in times of confinement through an ethnographic approach.

\section{METHODOLOGY}

This project was developed during short research stays where the background was established to analyse the current situation to question the inhabitants, while at the same time contrasting against the selfexperience.

\subsection{Micro-Ethnography and Auto-Ethnography}

Confinement implies new socio-spatial relations: of the subject with him or herself and with his or her family, as well as the subject with the domestic space. Ethnographies are used as a complex self-analysis that must be profound and critical to turn research into proposal and action.

A micro-ethnography was carried out through social cartographies and an auto-ethnography was developed through cognitive-body mapping and experience mapping to get a closer relationship to the people and their domestic situations [19]. The micro-ethnography focuses on particular aspects in a short period [20] and it allows to add a spatial dimension to discover the particularities within a full immersion [21], while visualizing an added value based on personal motivations [19], to find particular needs [22]. The auto-ethnography allows to prospect a qualitative research strategy [23] suitable for confinement, to approach the context from a subjective perspective of the researchers -actors themselves [24]. There is a capitalization on the affective and cognitive "experiences" of the person who developed knowledge based on reality due to his or her direct participation [23]. Here, the researcher is subject and object, an active participant capable of narrating the scene in which he or she works, having particular access to the observation [23], between the personal and the other interpretations [24].

\subsection{Social Cognitive Mapping}

Social cognitive maps are a way of telling stories where events are organized through visual, textual, or other means [25], and a way of communicating spatial information [26]. The narrative is fundamental, it is a way of finding the relationships between place, person, and time [27]. This includes narrated events, expressions, and interpretations of maps [28], critical reflections [29], dissemination of findings, data visualization, communication of information, and the exchange of stories [30]. This was used to approach family dynamics regarding shared spaces in specific time frames. The objective is to form socio-spatial cartography including different domestic spaces around the relations of the people who live there. The maps show the representation of conditions before and during confinement.

\subsection{Body Cognitive Mapping}

To represent new inhabited spaces through relations in confinement signifies working with the body. The body is the first territory on which to experience affective and emotional fluctuations and the first interphase in-between the subject and space [31]. The elaboration of a body cognitive mapping is based on the idea that when there is conflict in the lived spaces, there are pains that materialize directly on the body [31]. The researcher participants are prompted to develop their cognitive mapping where they play with the space and the emotions in direct relation to their bodies.

\subsection{Experience Mapping}

Mapping the experiences allows creating a relation between domestic spaces, the activities, and emotions, as its objective is to describe an effective method to understand and improve the user experience. This technique facilitates collaboration between stakeholders and designers, giving way to co-creation processes [32]. In this research, the experience maps were used to reach a deeper understanding of the mood of each family member regarding their family activities and relationships. The tools aforementioned were applied within two months in confinement, with a total number of 17 people. The group was made up of undergraduate students (Industrial Design and Architecture students) and graduate students of Architecture. Most of them belong to a medium-high socioeconomic group, 
and they live in medium to large size houses which allow for open spaces such as patios or terraces. Seven of them live by themselves, and the rest of the students shared inhabited spaces with their families.

\section{RESULTS AND DISCUSSION}

The used tools provide the identification of patterns that emerge from the phenomenon itself, from the individual analysis. The first finding refers to a progressive awareness around the issues of uses of space (before and during Covid-19). This is when clear socio-spatial dynamics around the definition of new personal and collective envision opportunities for change. Understanding the experience of each of the family members enables agreements, considerations and in many cases, through reflection on the proximity/privacy or inside/outside dualities, actions that lead to the resignification of spaces.

\section{Scopes \\ * Specialized area \\ - Non-specialized area \\ * External area \\ * Complementary area \\ Storage area}

\section{Relations \\ - Nearby \\ - - Contiguous \\ .... Posible}

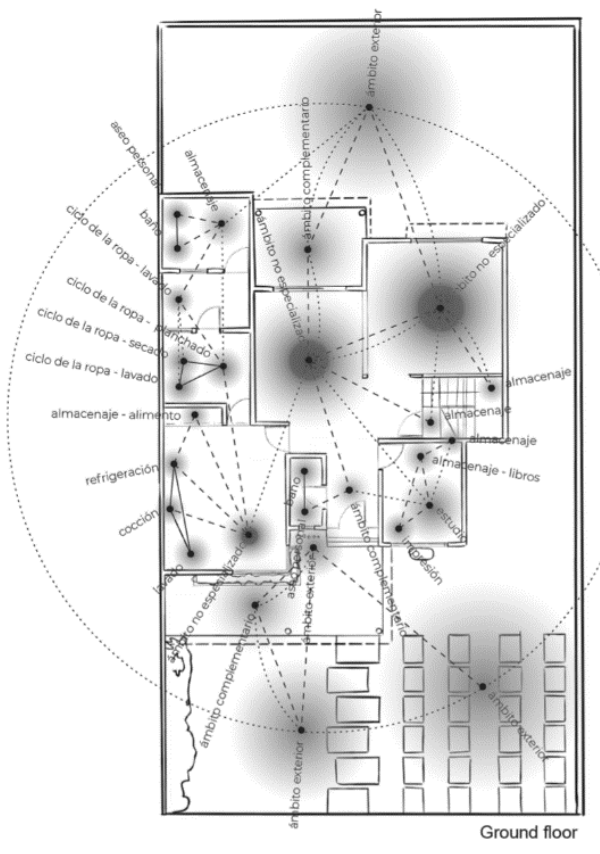

Figure 1. Example of Socio-Spatial Cartography (A). Relationships between housing areas

Unravelling the emotions, from the mapping of the body, allows for changes not only in the relationship with the inhabited space but with the body itself, establishing and increasing self-love.

These processes show the transition from an initial condition of bewilderment (at the beginning of the confinement), to a moment of empowerment and improvement based on creativity that allows the space to be adapted to new demands, to reappropriate it, and to regain security and serenity. The feeling of bewilderment and anxiety, in some cases, is accompanied by a greater concern for "the other," in a more socially conscious approach with attention to common spaces that are no longer usable. The repetition of domestic and work actions in a single space becomes an obsessive condition that transcends the limits of its inhabited space and overflows into an external space marked by the absurd, oppressive and monotonous, due to housing model conditions. 


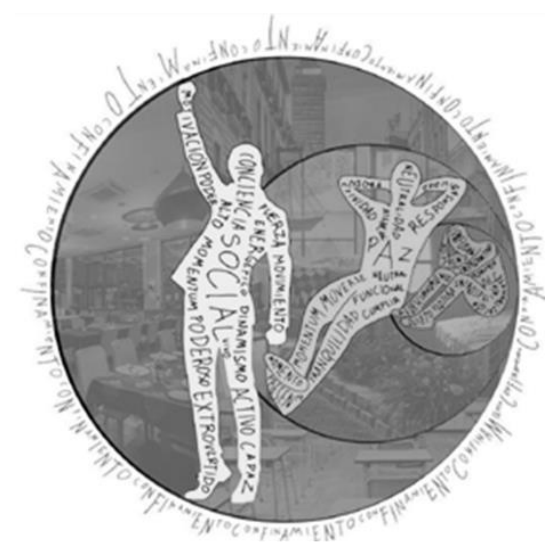

Figure 2. Example of Body Cognitive Mapping (B)

For some students, there was an awakening of a gender consciousness linked to spatial appropriation: before confinement, the individual room was essential for privacy and autonomy. During the confinement, leaving the room and expanding to other more public spaces in the house created a feeling of emancipation and liberation. The domestic space is analysed as the place of the process of role attribution, as was found by reviewing the conditions imposed by confinement.

Using experience mapping helped researcher students to understand the importance of self-e insights. They discovered that spaces could improve by allowing for self-awareness tools, which lead to redesign the domestic space improving their daily interaction with others.

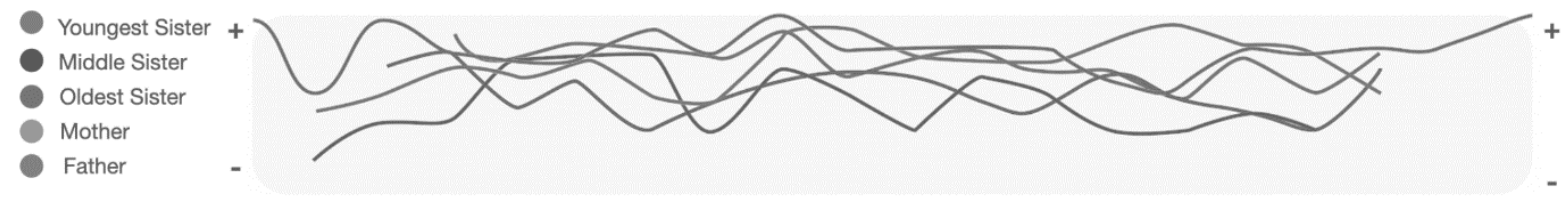

Figure 3. Example of Experience Mapping (C) of a common day in confinement

\section{CONCLUSIONS}

Family relationships were affected by space, and space was affected by the type of relationships. The confinement implies new socio-spatial relationships: that of the subject with himself or herself, and that of the subject with their family, also of the individual with the house itself. Analysing the above is possible with the use of auto-ethnography tools and micro ethnography: the first allows self-reflection in the confinement and reflection with the other in the same space, while the second allows the reflection on the specific problem of coexistence in the confinement (from the self to the we-family). Both tools, when used in a spatial context, can have a high value of "truth" and authenticity by eliminating the interpretation of others and judgment value. In addition, self-experimentation produces a greater understanding of the tools that will undoubtedly lead to a more empathetic attitude when collaboratively returning to fieldwork or when designing new domestic spaces.

The results obtained contribute to rethinking the domestic space beyond confinement. From academic experience, the use of autoethnographic and micro-ethnographic tools helped student researchers to understand how they experienced the theory of spaces first-hand. There was no need for interpretations, but self-knowledge and self-awareness. In addition, focusing on the specific topic of micro-ethnography allows one to reach a detailed and deep understanding of where new questions arise regarding the conception and categorization of spaces to satisfy new needs and desires. The application of the aforementioned tools within the family domestic space allowed researchers to articulate possible solutions based on an analysis that was not only experienced first-hand but also helped understand the terms of other relatives through their interactions and the space they share. For both students' researchers and teachers, new questions were triggered regarding the role assigned to the designer in confinement and beyond confinement, where roles are exchanged and assumed in new ways. Where spaces are transformed through self-awareness and observation. 


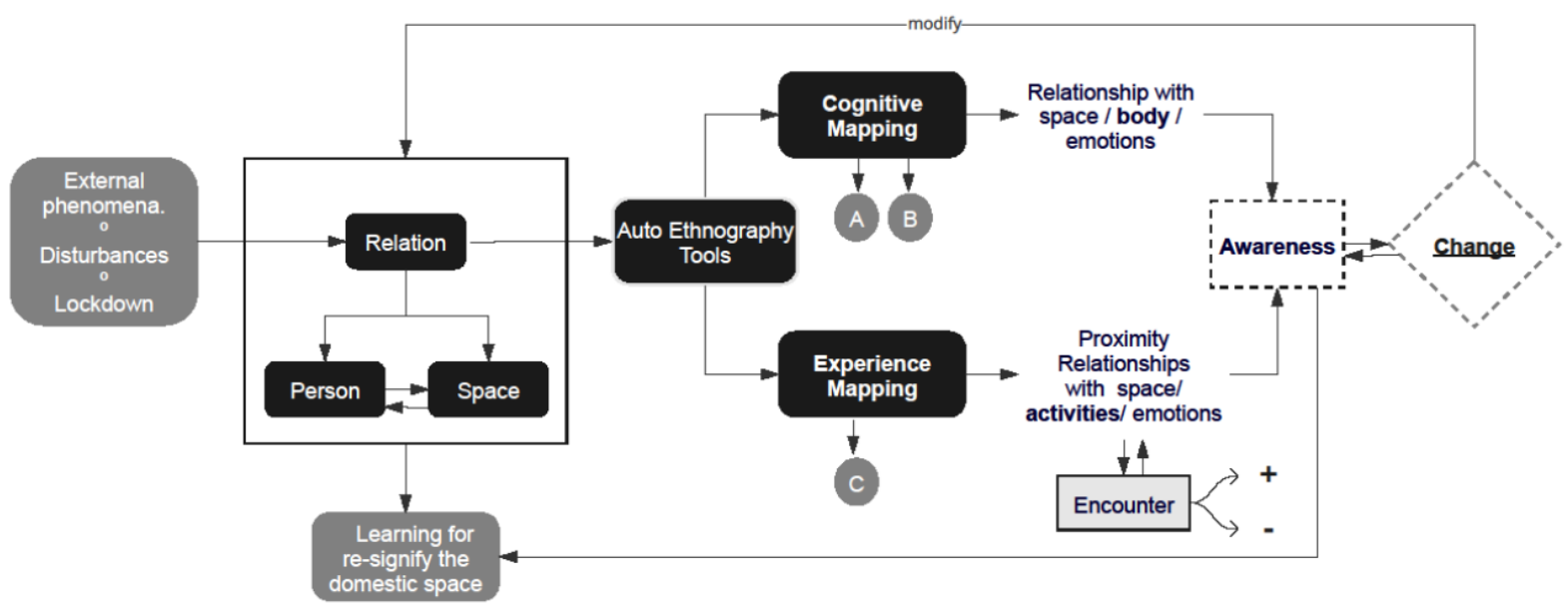

Figure 4. Autoethnographic analysis model and re-signification of space

As a final conclusion, as explained graphically according to the model in Figure 4, it can be observed how the ethnographic tools of cognitive and experience mapping, self-applied by the same research subject, facilitate reflection on the body/space relationships mediated by emotions, and close relationships with other people, in the same space, mediated by activities and other emotions. Also, some encounters can represent positive or negative experiences, thereby generating self-awareness leading to change. This, in turn, has repercussions on the initial space/person relationship in the form of learning that implies the resignification of the domestic space.

\section{REFERENCES}

[1] WHO. Emergencies: Novel Coronavirus 2019; 2020, (WHO: Geneva, Switzerland).

[2] Hou C., Chen J., Zhou Y., Hua L., Yuan J., He S., Guo Y., Zhang S., Jia Q., Zhao C., Zhang J., $\mathrm{Xu}$ G., and Jia E. The effectiveness of the quarantine of Wuhan city against the Corona Virus Disease 2019 (COVID-19): well-mixed SEIR model analysis. 2020, Journal of Medical Virology $0-3$.

[3] Ferguson, N. M., Laydon D., Nedjati-Gilani G., Imai N., Ainslie K., Baguelin M., Bhatia S., Boonyasiri A., Cucunubá Z., Cuomo-Dannenburg G., Dighe A., Dori-gatti I., Fu H., Gaythorpe K., Green W., Hamlet A., Hinsley W., Okell L. C., Van Elsland S., Thompson H., Verity R., Volz E., Wang H., Wang Y., Gt Walker P., Walters C., Winskill P., Whittaker C., Donnelly C. A., Riley S. and Ghani A. C. Impact of non-pharmaceutical interventions (NPIs) to reduce COVID19 mortality and healthcare demand. 2020, (Faculty of Medicine / School of Public Health / Imperial College London).

[4] Boyraz G. and Legros D. N. Coronavirus disease (COVID-19) and traumatic stress: Probable risk factors and correlates of posttraumatic stress disorder. 2020, Journal of Loss \& Trauma, 25(6-7),

[5] Casagrande M., Favieri F., Tambelli R., and Forte G. The enemy who sealed the world: Effects quarantine due to the COVID-19 on sleep quality, anxiety, and psychological distress in the Italian population. 2020, Sleep Medicine. (CR)

[6] Sun L., Sun Z., Wu L., Zhu Z., Zhang F., Shang Z. et al. Prevalence and risk factors of acute posttraumatic stress symptoms during the COVID-19 outbreak in Wuhan, China. 2020, MedRxiv.

[7] Baiano C., Zappullo I., and Conson M. Tendency to Worry and Fear of Mental Health during Italy's COVID-19 Lockdown. 2020, International Journal of Environmental Research and Public Health, 17(16), 5928. MDPI AG.

[8] Wagers S. Domestic violence growing in the wake of coronavirus outbreak. 2020, The Conversation. Retrieved April 11. (CR)

[9] Fry-Bowers E. K. Children are at risk from COVID-19. 2020, J. Pediatr. Nurs., 53, A10-A12. (CR)

[10] Garcia de Avila M., Hamamoto Filho P., Jacob F., Alcantara L., Berghammer M., Jenholt Nolbris M., Olaya-Contreras P. et al. Children's Anxiety and Factors Related to the COVID-19

Pandemic: An Exploratory Study Using the Children's Anxiety Questionnaire and the Numerical 
Rating Scale. 2020, International Journal of Environmental Research and Public Health, 17(16), 5757.

[11] White M. P., Alcock I., Grellier J., Wheeler B. W., Hartig T., Warber S. L., and Fleming L. E. Spending at least 120 minutes a week in nature is associated with good health and wellbeing. Scientific Reports, 2019, 9(1), 7730.

[12] Allam Z. and Jones D. Pandemic stricken cities on lockdown. Where are our planning and design professionals [now, then and into the future]. Land Use Policy, 2020,

[13] Garber M. Homes actually need to be practical now: One of the ironies of social distancing is that it can put privacy in short supply. The Atlantic Retrieved, 2020, April 11.

[14] Rubin G. J. and Wessely S. The psychological effects of quarantining a city. BMJ, 2020, 368, $\mathrm{m} 313$.

[15] Ulrich R. S., Zimring C., Zhu X., DuBose J., Seo H. B., Choi Y. S., Quan X., and Joseph A. A. Review of the research literature on evidence-based healthcare design. Health Environ. Res. Des. J., 2008, 1, 61-125.

[16] Doménech-Gómez, N. Aplicación de técnicas cualitativas y cuantitativas para recoger la respuesta del usuario frente a un espacio arquitectónico. 2015 (Universidad Politécnica de Valencia. Escuela Técnica Superior de Gestión en la Edificación - Escuela Técnica Superior de Gestión).

[17] Rogers D. and Power E. Housing policy and the COVID-19 pandemic: the importance of housing research during this health emergency. International Journal of Housing Policy, 2020, 20:2, 177.

[18] D’Alessandro D., Gola M., Appolloni L., Dettori M., Fara G. M., Rebecchi A., Settimo G. and Capolongo S. COVID-19 and living space challenge. Well-being and public health recommendations for a healthy, safe, and sustainable housing. Acta Biomed. 2020, 91 (Suppl. 9).

[19] Wilson S. and Zamberlan L. Design for an Unknow Future: Amplified Roles for Collaboration, New Design Knowledge and Creativity. Design Issues, 2015, 31(2), 3-15.

[20] Bryman A. Social research methods. 2008 (Oxford University Press, Oxford).

[21] Hammersley M. and Atkinson P. Ethnography: principles in practice, 2007 (Taylor \& Francis Ltd.).

[22] Maya M., Cobreros C., Ontiveros E., and Biondi S. Community Collaboration for Product Design (Co-Co Design): An Academic Alternative for Social Innovation. International conference on Engineering and Product Design Education 12-13 September 2019, Department of Design, Manufacturing and Engineering Management, University of Strathclyde, United Kingdom, 2019.

[23] Scribano A. and De Sena A. Construcción de Conocimiento en Latinoamérica: Algunas reflexiones desde la auto-etnografía como estrategia de investigación. 2009, 34, 1-15 (Cinta Moebio).

[24] Montero-Sieburth M. La auto-etnografía como una estrategia para la transformación de la homogeneidad a favor de la diversidad individual en la escuela. 2006. (Univ. de MassachussetsBoston).

[25] Hohenthal J., Minoia P., and Pellikka P. Mapping meaning: Critical cartographies for participatory water management in Taita Hills, Kenya. Professional Geographer, 2017, 69:38395.

[26] Caquard S. Cartography I: Mapping narrative cartography. Progress in Human Geography, 2011, 37:135-44

[27] Ingold T. Being alive: Essays on movement, knowledge and description, 2011 (New York: Routledge).

[28] Caquard S. and Cartwright W. Narrative cartography: From mapping stories to the narrative of maps and mapping. The Cartographic Journal, 2014, 51, 101-06.

[29] Molden O. C. Short Take: Story-mapping Experiences. Field Methods, 2020, 32(2), 131-139.

[30] Berendsen M. E., Hamerlinck J. D., and Webster G. R. Digital story mapping to advance educational atlas design and enable student engagement. International Journal of GeoInformation, 2018, 7:125

[31] Cruz, D. T., Vázquez E., Ruales G., Bayón M., and García-Torres M. Mapeando el cuerpoterritorio. Guía metodológica para mujeres que defienden sus territorios, 2017 (Clacso, Quito)

[32] Samson S., Granath K., and Alger A. Journey Mapping the User Experience. 2017, 78(4), 459 (College \& Research Libraries). 